\title{
Pengaruh Gaya Kepemimpinan, Disiplin Kerja, Dan Motivasi Kerja Terhadap Kinerja Karyawan PT. LIMAS SURYA MAKMUR
}

\author{
Marceline Tania Agustine dan Edalmen \\ Program Studi Manajemen, Fakultas Ekonomi Universitas Tarumanagara Jakarta \\ Email:tania.marceline@yahoo.com
}

\begin{abstract}
The purpose of this research was to determine the effect of leadership style, work discipline, and work motivation on employee performance at PT. Limas Surya Makmur. The population in this study were all 59 employees of PT. Limas Surya Makmur. The sample research method uses a non-probability design, sampling techniques saturated with quantitative research and using questionnaires to collect data. The results showed that leadership style and work discipline gave a positive and significant influence on the performance of employees of PT Limas Surya Makmur and work motivation gave a positive but not significant effect on the performance of employees at PT. Limas Surya Makmur.
\end{abstract}

Keywords: Leadership style, work discipline, work motivation, employee performance.

Abstrak: Tujuan dari penelitian ini adalah untuk mengetahui pengaruh gaya kepemimpinan, disiplin kerja, dan motivasi kerja terhadap kinerja karyawan di PT. Limas Surya Makmur. Populasi dalam penelitian ini adalah seluruh karyawan PT. Limas Surya Makmur yang berjumlah 59 orang. Metode penelitian sampel menggunakan desain non probabilitas yaitu teknik sampling jenuh dengan penelitian kuantitatif dan menggunakan kuesioner untuk mengumpulkan data. Hasil penelitian menunjukkan bahwa gaya kepemimpinan dan disiplin kerja memberi pengaruh positif dan signifikan terhadap kinerja karyawan PT Limas Surya Makmur serta motivasi kerja memberi pengaruh positif namun tidak signifikan terhadap kinerja karyawan di PT. Limas Surya Makmur.

Kata kunci: Gaya Kepemimpinan, Disiplin Kerja, Motivasi Kerja, Kinerja Karyawan.

\section{LATAR BELAKANG}

Keberhasilan perusahaan dapat bergantung pada kinerja karyawan di dalam perusahaan itu. Dengan gaya kepemimpinan yang baik akan mendorong dan menghasilkan kinerja yang tinggi oleh bawahannya. Disiplin kerja dibutuhkan perusahaan untuk mencapai tujuannya, karena disiplin kerja yang tertanam pada setiap karyawan akan mempengaruhi peningkatan kinerja pada perusahaan. Motivasi dibutuhkan oleh setiap karyawan sebagai dorongan atau pancingan untuk mendapatkan kinerja yang lebih baik. Setelah dilakukan wawancara dengan beberapa karyawan PT Limas Surya Makmur maka disimpulkan bahwa adanya kelemahan gaya kepemimpinan. Pemimpin tidak menerapkan peraturan secara tegas serta adanya 
pembagian kerja yang tidak sesuai sehingga hasil yang diperoleh tidak efisien dan efektif. Pengawasan yang kurang menyebabkan keterlambatan perolehan hasil kerja sehingga berlanjut pada keterlambatan pengiriman kayu. Pemimpin juga tidak tegas dalam memberi tindakan terhadap karyawan yang tidak bekerja sesuai standar. Dalam hasil wawancara juga ada pendapat karyawan bahwa pemimpin memperlakukan karyawan secara tidak adil antara yang satu dengan yang lainnya.

Faktor lain yang mempengaruhi kinerja karyawan di PT Limas Surya Makmur adalah disiplin kerja. Dari hasil wawancara dengan beberapa karyawan, disimpulkan adanya disiplin kerja yang kurang maksimal di perusahaan ini. Pada perusahaan, penurunan disiplin kerja ditunjukkan dengan adanya absensi karyawan yang meningkat, pekerjaan yang tidak dikerjakan sesuai standar kerja, jam kerja yang belum jelas, serta disiplin dalam penggunaan alat keselamatan dalam bekerja.

PT Limas Surya Makmur juga perlu memperhatikan adanya penurunan motivasi yang berdampak pada penurunan kinerja pada perusahaan. Dari hasil wawancara dengan beberapa karyawan perusahaan ditemukan adanya motivasi yang rendah pada karyawan, beberapa karyawan merasa tidak adanya jenjang karier pada perusahaan adapula yang merasa tidak diperhatikan. Beberapa karyawan juga merasa kurangnya kompensasi dari perusahaan yang mengakibatkan karyawan bermalas-malasan dalam melakukan pekerjaannya. Adanya karyawan yang tidak nyaman dengan pembagian kerja, merasa tidak cocok dengan pekerjaannya sehingga menurunkan motivasi kerja.

Berdasarkan dengan hal-hal yang telah diuraikan di atas dan meilihat pentingnya gaya kepemimpinan, disiplin dan motivasi dalam meningkatkan kinerja karyawan di PT Limas Surya Makmur maka peneliti berniat untuk mengadakan penelitian dengan judul "Pengaruh Gaya Kepemimpinan, Disiplin dan Motivasi terhadap kinerja karyawan PT Limas Surya Makmur."

\section{KAJIAN TEORI}

\section{Gambaran Umum Teori}

Acuan dari beberapa ahli, memberikan pernyataan Kinerja karyawan menentukan keberhasilan atau kegagalan sebuah organisasi. Kinerja karyawan didefinisikan sebagai kegiatan yang secara formal diakui sebagai bagian dari pekerjaan dan juga berkontribusi pada tujuan organisasi (Borman dan Motowidlo, 1997). Kepemimpinan mengacu pada sebuah kemampuan seorang pemimpin untuk memotivasi yang memungkinkan anggota organisasi untuk berkontribusi dan mencapai keberhasilan dan keefektifan organisasi (Anand dan Udaya-Suriyan, 2010). Disiplin kerja adalah perilaku dan tindakan yang sesuai dengan aturan perusahaan, baik itu peraturan tertulis atau tidak tertulis. Disiplin juga merupakan kesadaran dan kemauan seseorang untuk mematuhi semua aturan hukum dan norma sosial yang berlaku (Pacitti, 2011). Motivasi kerja adalah "set of energetic forces that originate both within as well 
as beyond an individual's being, to initiate work-related behavior, and to determine its form, direction, intensity, and duration" (Pinder, 2008).

\section{Definisi Konseptual Variabel}

Kinerja karyawan adalah hasil kerja karyawan selama periode tertentu yang telah disepakati sebelumnya berdasarkan tingkah laku kerja, kualitas dan kuantitas outcome, kehadiran karyawan, efisiensi dan efektivitas pekerjaan dalam melaksanakan tugas yang diberikan oleh perusahaan (Abbas dan Yaqoob, 2009, h. 269); (Anitha, 2014, h. 309); (Maryoto, 2000, h. 91); (Mathis and Jackson,2009); (Sutrisno, 2012, h. 151); dan (Mangkunegara, 2009, h. 67).

Gaya kepemimpinan, dapat disimpulkan bahwa gaya kepemimpinan adalah Tindakan seorang pemimpin untuk mempengaruhi, mengerahkan, memotivasi, mengendalikan, serta mencapai tujuan ke bawahannya (Ivancevich, 2014, h. 435); (Kippenberger, 2002, h. 6); (Purwanto, 2006, h. 24); (Rivai dan Mulyadi, 2013, h. 42); (Goleman, 1998, h. 12); dan ( Mgbere, 2009, h.187).

Disiplin kerja adalah suatu peraturan atau norma sosial untuk dipatuhi karyawan sebagai upaya meningkatkan tata tertib dalam perusahaan (Dessler, 2015, h. 473); (Sindhu, 2006, h.171); (Afandi, 2016, h. 1); (Rivai, 2011); dan (Fanthoni, 2006).

Motivasi kerja adalah dorongan dari diri sendiri atau orang lain untuk melaksanakan tugas dan tanggung jawab yang akan dicapai (Faustino Cardoso Gomes, 2010, h. 177); (Latham dan Pinder, 2005, h. 230); (Sedarmayanti, 2012, h. 233); dan (Darmadi, 2018, h. 294).

\section{Hubungan antar Variabel}

\section{Kaitan Gaya Kepemimpinan terhadap Kinerja Karyawan}

Gaya kepemimpinan diartikan sebagai kemampuan seorang pemimpin untuk bekerja dalam sekelompok pekerja untuk mencapai tujuan (Mgbere, 2009). Gaya kepemimpinan merupakan faktor utama pendukung dan pendorong dalam memimpin karyawan untuk meningkatkan kinerja. Keberhasilan suatu organisasi sangat bergantung pada gaya kepemimpinan yang dimiliki oleh organisasi itu. Pemimpin yang berhasil dapat menghasilkan kinerja yang tinggi. Pemimpin harus mengatur karyawan sebaik mungkin agar dapat meningkatkan kinerja karyawan. Karyawan juga dapat meningkatkan kinerjanya jika pemimpinnya memiliki gaya kepemimpinan yang dapat diterima oleh semua karyawan di dalam organisasi.

\section{Kaitan Disiplin Kerja terhadap Kinerja Karyawan}

Disiplin Kerja Menurut (Singodimedjo, 2013), menyatakan bahwa disiplin adalah sikap kemauan seseorang untuk taat dan patuh terhadap norma peraturan yang berlaku. Kedisiplinan merupakan fungsi operatif manajemen sumber daya manusia yang sangat penting, jika disiplin kerja semakin tinggi maka akan menghasilkan kinerja yang tinggi (Hasibuan, 2014). Karyawan dengan disiplin kerja yang baik terkait waktu, kehadiran, 
keamanan, dan lain-lain akan menjadikan perusahaan mencapai hasil yang optimal. Karyawan yang memiliki disiplin kerja yang baik seperti ini juga menghasilkan kinerja yang tinggi.

\section{Kaitan Motivasi Kerja terhadap Kinerja Karyawan}

Motivasi kerja menurut (Luthans, 1998) adalah suatu prosedur yang mengeluarkan energi, stimulasi, bergerak, dan mengarahkan tindakan serta kinerja. Motivasi memberi pengaruh untuk kinerja, karena jika karyawan termotivasi maka mereka akan lebih berupaya dan menghasilkan kinerja yang tinggi. Karyawan akan melakukan sesuatu untuk sebuah organisasi jika termotivasi untuk mencapai tujuan pribadi, sehingga karyawan akan melakukan kinerja yang tinggi. Motivasi yang diberikan perusahaan akan mendorong karyawan untuk melakukan sesuatu untuk perusahaan.

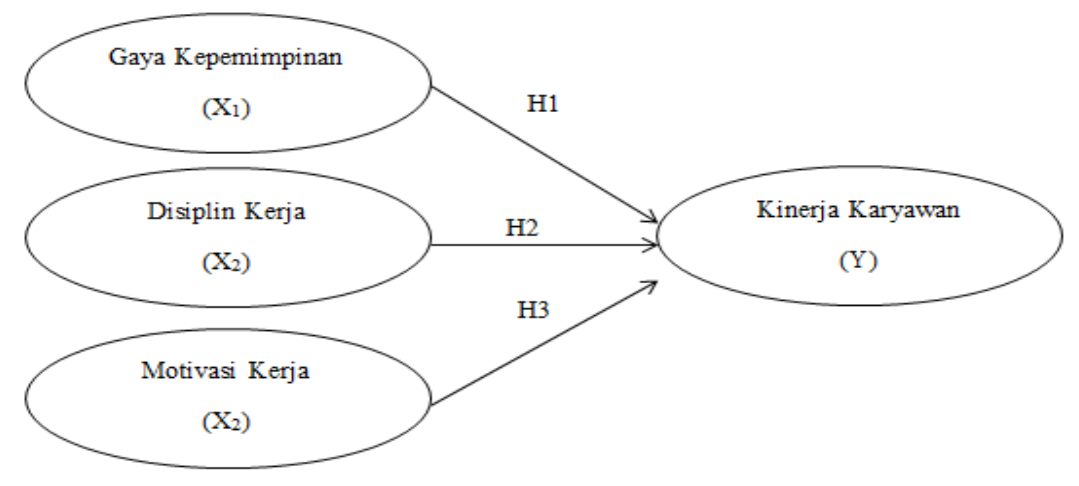

Gambar 2.2

Model Penelitian

Hipotesis yang diajukan dalam penelitian ini adalah sebagai berikut:

H1 : Gaya Kepemimpinan (X1) memiliki pengaruh terhadap Kinerja Karyawan (Y)

H2 : Disiplin Kerja (X2) memiliki pengaruh terhadap Kinerja Karyawan (Y) H3 : Motivasi Kerja (X3) memiliki pengaruh terhadap Kinerja Karyawan (Y)

\section{METODOLOGI}

Subjek penelitian pada penelitian ini adalah PT. Limas Surya Makmur, sedangkan yang menjadi objek penelitian ini adalah hal-hal yang dipilih oleh penulis sebagai dasar penelitian yaitu gaya kepemimpinan sebagai variabel bebas $\mathrm{X}_{1}$, disiplin kerja sebagai variabel bebas $\mathrm{X}_{2}$, motivasi kerja sebagai variabel bebas $\mathrm{X}_{3}$, dan kinerja karyawan sebagai variabel terikat $\mathrm{Y}$.

Dalam melakukan penelitian, populasi merupakan bagian penting yang harus ditentukan. Populasi adalah kumpulan dari keseluruhan objek, pengukuran, atau 
individu yang sedang dikaji dalam suatu penelitian, populasi tidak hanya sebatas pada kumpulan individu atau kumpulan orang-orang melainkan seluruh ukuran, hitungan, atau kualitas yang fokus menjadi kajian penelitian (Harinaldi, 2005). Dalam penelitian ini yang menjadi populasi adalah seluruh karyawan PT Limas Surya Makmur yang berjumlah 59 orang.

Teknik pemilihan sampel merupakan sebuah teknik untuk menentukan sampel. Teknik pemilihan sampel adalah cara yang digunakan untuk menentukan sampel agar jumlahnya sesuai dengan sampel yang akan dijadikan sumber data sebenarnya (Margono, 2004). Secara umum teknik pemilihan sampel terdiri dari dua macam yaitu desain probabilitas dan non probabilitas. Pada penelitian ini, penulis menggunakan desain non probabilitas yaitu sampling jenuh. Sampling jenuh adalah cara pengambilan sampel dengan mengambil semua jumlah populasi sebagai sampel (Supriyanto \& Maharani, 2013)

Subyek pada penelitian ini adalah seluruh karyawan PT. Limas Surya Makmur dengan total penyebaran kuesioner sebanyak 59 kuesioner. Responden pada penelitian ini dibagi menjadi beberapa kategori yaitu jenis kelamin, pendidikan terakhir, dan usia.

\section{Hasil Uji Statistik}

\section{Uji validitas dan reliabilitas}

Penelitian ini menggunakan perangkat lunak SMART-PLS3 karena PLS-SEM, Uji validitas konvergen dengan program smartPLS 3.0 dapat dilihat dari nilai loading factor untuk setiap indikator konstruk. Pada validitas konvergen dengan parameter loading factor harus memiliki nilai $>0.70$ untuk exploratory research serta nilai $A V E>0.50$. Berdasarkan hasil analisis validitas konvergen, semua pernyataan variabel memiliki loading factor >0.7. Sehingga dapat disimpulkan bahwa keempat variabel dalam penelitian itu adalah valid. Berdasarkan hasil Cronbach's Alpha, nilai semua variabel $>0.6$ sehingga dapat disimpulkan bahwa ketiga variabel dalam penelitian ini reliabel.

\section{Uji $R$-Square $\left(\mathbf{R}^{2}\right)$}

$R$-Square digunakan untuk menjelaskan pengaruh variabel laten eksogen tertentu terhadap variabel laten endogen terkait adanya pengaruh subtantive. Jarak $\mathrm{R}^{2}$ adalah 0 hingga 1 dimana 1 mengartikan akurasi prediktif yang sempurna. Berdasarkan hasil pengujian koefisien determinasi pada Tabel 4.14, menunjukkan bahwa variabel Y yaitu kinerja karyawan mampu dijelaskan oleh variabel gaya kepemimpinan $\left(\mathrm{X}_{1}\right)$, disiplin kerja $\left(\mathrm{X}_{2}\right)$, dan motivasi kerja $\left(\mathrm{X}_{3}\right)$ sebesar $74,5 \%$ dan sisanya $25,5 \%$ dijelaskan oleh variabel lain.

Tabel 2. Hasil Pengujian Hipotesis 


\begin{tabular}{|l|c|c|c|c|c|}
\hline & Original & Sample & $\begin{array}{c}\text { Standard } \\
\text { Deviation } \\
\text { Sample } \\
(\mathbf{S T D E})\end{array}$ & $\begin{array}{c}\text { T Statistic } \\
(\mathbf{| O / S T D E} \\
\mathbf{V} \mid)\end{array}$ & $\begin{array}{c}\mathbf{P} \\
\text { Values }\end{array}$ \\
\hline $\mathrm{X} 1 \rightarrow \mathrm{Y}$ & 0.518 & 0.507 & 0.114 & 4.540 & 0.000 \\
\hline $\mathrm{X} 2 \rightarrow \mathrm{Y}$ & 0.295 & 0.278 & 0.106 & 2.787 & 0.006 \\
\hline $\mathrm{X} 3 \rightarrow \mathrm{Y}$ & 0.172 & 0.200 & 0.105 & 1.589 & 0.113 \\
\hline
\end{tabular}

\section{DISKUSI}

Penelitian yang dilakukan terhadap keseluruhan karyawan PT. Limas Surya Makmur dengan jumlah 59 orang menggunakan data primer yang diperoleh dengan menyebarkan kuesioner. Hasil pengujian menunjukkan bahwa gaya kepemimpinan berpengaruh positif dan signifikan terhadap kinerja karyawan, begitu juga dengan disiplin kerja yang memiliki pengaruh positif dan signifikan terhadap kinerja karyawan, dan motivasi kerja yang memiliki pengaruh positif namun tidak signifikan terhadap kinerja karyawan.

Berdasarkan hasil analisis data uji convergent validity untuk variabel kinerja karyawan menunjukkan bahwa indikator kedua dengan pernyataan "Menyelesaikan pekerjaan tidak terduga dengan tepat waktu", menjadi indikator yang mempunyai pengaruh paling besar terhadap variabel kinerja karyawan, sedangkan indikator pertama dengan pernyataan "Mengerti pekerjaan dan bagaimana melakukannya", menjadi indikator yang mempunyai pengaruh paling sedikit terhadap variabel kinerja karyawan.

Kemudian untuk variabel gaya kepemimpinan menunjukkan bahwa indikator kedua dengan pernyataan "Menghormati pemimpin.", menjadi indikator yang mempunyai pengaruh paling besar terhadap variabel gaya kepemimpinan, sedangkan indikator kelima dengan pernyataan "Pemimpin memiliki sikap yang ramah dan mudah didekati", menjadi indikator yang mempunyai pengaruh paling sedikit terhadap variabel gaya kepemimpinan.

Selanjutnya untuk variabel disiplin kerja menunjukkan bahwa indikator kedelapan dengan pernyataan "Keadilan yang baik akan menghasilkan disiplin yang baik", menjadi indikator yang mempunyai pengaruh paling besar terhadap variabel disiplin kerja, sedangkan indikator kedua dengan pernyataan "Penggunaan waktu secara efektif", menjadi indikator yang mempunyai pengaruh paling sedikit terhadap variabel disiplin kerja.

Terakhir untuk variabel motivasi kerja menunjukkan bahwa indikator pertama dengan pernyataan "Upaya yang berkomitmen untuk memotivasi karyawan", menjadi 
indikator yang mempunyai pengaruh paling besar terhadap variabel motivasi kerja, sedangkan indikator kedua dengan pernyataan "Melakukan praktik rutin motivasi karyawan", menjadi indikator yang mempunyai pengaruh paling sedikit terhadap variabel motivasi kerja.

Hasil penelitian tersebut menunjukkan bahwa gaya kepemimpinan merupakan pengaruh yang positif dan signifikan terhadap kinerja karyawan, oleh karena itu dengan adanya gaya kepemimpinan yang baik mempunyai kinerja karyawan yang tinggi pula. Disiplin kerja merupakan pengaruh yang positif dan signifikan terhadap kinerja karyawan, oleh karena itu karyawan dengan disiplin kerja yang baik terkait waktu, kehadiran, dan lain-lain akan menjadikan perusahaan mencapai hasil yang optimal. Motivasi kerja merupakan pengaruh yang positif tetapi tidak signifikan terhadap kinerja karyawan di PT Limas Surya Makmur, sehingga mengartikan bahwa dengan adanya motivasi kerja yang baik tidak memberikan pengaruh atau memberikan pengaruh kecil terhadap kinerja karyawan.

Berdasarkan uraian yang terdapat pada bagian analisis dan pembahasan, maka dapat disimpulkan bahwa:

1. Gaya kepemimpinan mempunyai pengaruh yang positif dan signifikan terhadap kinerja karyawan.

2. Disiplin kerja mempunyai pengaruh yang positif dan signifikan terhadap kinerja karyawan.

3. Motivasi Kerja mempunyai pengaruh yang positif namun tidak signifikan terhadap kinerja karyawan.

\section{DAFTAR PUSTAKA}

Abbas, Q., \& Yaqoob, S, (2009). "Effect of leadership development on employee performance in Pakistan". Pakistan: Economic and Social Review, 269-292.

Afandi, Pandi. (2016). "Concept \& Indicator Human Resource Management For Management Research". Yogyakarta: Deepublish.

Anand, R. and Udaya-Suriyan, G. (2010), "Emotional intelligence and its relationship with leadership practices", International Journal of Business and Management, Vol. 5 No. 2, pp. 65-76.

Anitha, J., (2014). "Determinants of employee engagement and their impact on employee performance". International Journal of Productivity and Performance Management, 308-323.

Borman, W.C. and Motowidlo, S.J. (1997), "Task performance and contextual performance: the meaning for personnel selection research", Human Performance, Vol. 10 No. 2, pp. 99-109.

Darmadi. (2018),"Manajemen Sumber Daya Manusia Kekepalasekolahan”, Edisi Pertama. Yogyakarta: Deepublish. 
Dessler, Gary., (2015). "Human Resource Management”, International Edition, 14th Edition, Pearson Education, Inc.

Fachreza., Musnadi, Said., Abd Majid., M. Shabri.(2018). Pengaruh Motivasi Kerja, Lingkungan Kerja,

Dan Budaya Organisasi Terhadap Kinerja Karyawan Dan Dampaknya Pada Kinerja Bank Aceh

Syariah Di Kota Banda Aceh. Jurnal Magister Manajemen Fakultas Ekonomi dan Bisnis

Unsyiah, Vol. 2, No. 1

Fachreza., Musnadi, Said., Abd Majid., M. Shabri.(2018). Pengaruh Motivasi Kerja, Lingkungan Kerja,

Dan Budaya Organisasi Terhadap Kinerja Karyawan Dan Dampaknya Pada Kinerja Bank Aceh

Syariah Di Kota Banda Aceh. Jurnal Magister Manajemen Fakultas Ekonomi dan Bisnis

Unsyiah, Vol. 2, No. 1

Fachreza., Musnadi, Said., Abd Majid., M. Shabri.(2018). Pengaruh Motivasi Kerja, Lingkungan Kerja,

Dan Budaya Organisasi Terhadap Kinerja Karyawan Dan Dampaknya Pada Kinerja Bank Aceh

Syariah Di Kota Banda Aceh. Jurnal Magister Manajemen Fakultas Ekonomi dan Bisnis

Unsyiah, Vol. 2, No. 1

Fathoni, A. (2006). "Organisasi dan Manajemen Sumber Daya Manusia". Jakarta: Rineka Cipta.

Goleman, D. (1998), "Working with Emotional Intelligence", Bantam Books, New York, NY.

Harinaldi, Dr. Ir. M.Eng. (2005)., “ Prinsip - Prinsip Statistik Untuk Teknik Dan Sains ", Jakarta: Erlangga.

Hasibuan, Malayu S.P. (2014). “Manajemen Dasar Pengertian dan Masalah”. Jakarta: Bumi Aksara

Ivancevich, John M., et al., (2014). "Organizational Behavior and Management". 10th Edition. New York: McGraw-Hill Education.

Kippenberger, Tony. (2002). "Leadership Styles", United Kingdom: Capstone Publishing.

Latham, G. P. \& Pinder, C. C. (2005). "Work motivation theory and research at the dawn of the twenty-first century." Annual Review of Psychology, 04, 230-516.

Luthans, F. (1998). "Organizational Behavior”. 8th ed. Boston: Irwin McGraw-Hill.

Mangkunegara, Anwar Prabu. (2009). "Manajemen Sumber Daya Manusia”. Cetakan Ksembilan. Bandung: PT. Remaja Rosdakarya.

Margono. (2004). "Metodologi Penelitian Pendidikan". Jakarta: PT Rineka Cipta.

Maryoto, Susilo, (2000). "Manajemen Sumber Daya Manusia". Yogyakarta: BPFE UGM.

Mathis, R. L and Jackson, J. H.(2009). "Human Resource Management”. Mason, OH, USA: South-Western Cengage Learning. 
Mgbere, O. (2009), "Exploring the relationship between organizational culture, leadership styles and corporate performance: an overview", Journal of Strategic Management Education, Vol. 5 Nos 3/4, pp. 187-201.

Pacciti. (2011). "Efficiency Wages, Unemployement, And Labour Discipline”. Journal of Business \& Economic Research, 9.3, pp.1-10

Pinder, C.C, (2008). "Work motivation in organizational behavior (2nd edition)". New York: Psychology Press.

Purwanto, Djoko. (2006). "Komunikasi Bisnis". Jakarta: Erlangga

Rivai, V. (2011). "Manajemen Sumber Daya Manusia untuk Perusahaan: dari Teori ke Praktik". Jakarta: Raja Grafindo Persada.

Rivai, V. Dan Muljadi, D. (2013). "Kepemimpinan dan Perilaku Organisasi", Edisi Ketiga. Jakarta: Rajawali Pers.

Sedarmayanti. (2012), "Human Resources and Work Productivity". Bandung: Bandar Maju.

Sindu Mulianto, dkk, (2006). "Panduan Lengkap Supervisi Diperkaya Perspektif Syariah", Jakarta: PT Elex Media Komputindo.

Singodimedjo dalam Edi Sutrisno, (2010). "Manajemen Sumber Daya Manusia Pengaruh Disiplin Kerja terhadap Prestasi Kerja". Jakarta : Kencana.

Sutrisno, Edy. (2012). "Manajemen Sumber Daya Manusia”. Edisi 1. Cetakan Keempat. Prenada Media Group. Jakarta.

Supriyanto, Achmad Sani dan Vivin Maharani. (2013). "Metode Penelitian Sumber Daya Manusia Teori, Kuisioner, dan Analisis Data". Malang: UIN-Malang Press. 